УДК 538.975: 539.231

ISSN 1606-867X

DOI: https://doi.org/10.17308/kcmf.2019.21/2362

Поступила в редакцию 21.10.2019

Подписана в печать 15.11.2019

\title{
Тонкие металлические пленки с дисперсионно-твердеющими магнитными слоями сплава $\mathrm{Fe}-\mathrm{Cr}-\mathrm{Co}$
}

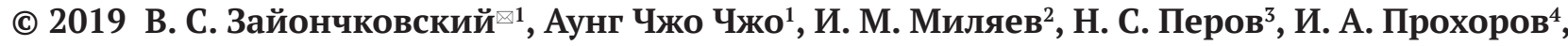 \\ А. А. Климов ${ }^{5}$ А. В. Андреев ${ }^{5,6}$ \\ ${ }^{1}$ Калужский филиал МГТУ им. Н.Э. Баумана \\ ул. Баженова, 2, 248000 Калуга, Российская Федерация \\ ${ }^{2}$ Институт металлургии и материаловедения им. А.А. Байкова РАН \\ Ленинский проспект, 49, 119334 Москва, Российская Федерация \\ ${ }^{3}$ Московский государственный университет им. М.В. Ломоносова \\ Ленинские горы, 1, 119991 Москва, Российская Федерация \\ ${ }^{4}$ Институт кристаллографии им. А.В. Шубникова ФНИЦ “Кристаллография и фотоника” РАН \\ Ленинский проспект, 59, 119333, Москва, Российская Федерация \\ ${ }^{5}$ Институт радиотехники и электроники им. В.А. Котельникова РАН \\ ул. Моховая, 11, корп.7, 125009 Москва, Российская Федерация \\ ${ }^{6}$ Национальный исследовательский университет «МЭИ» \\ Красноказарменная, 14, 111250 Москва, Российская Федерация
}

\begin{abstract}
Аннотация. Магнетронным напылением на кремниевые монокристаллические подложки получены трехслойные пленки, содержащие слой дисперсионно-твердеющего сплава (СДTC) на основе системы Fe-Cr-Co. Установлено, что толщина слоя меди, который обеспечивает сохранность дисперсионно-твердеющего сплава СДТС на подложке после отжига, должна быть не менее толщины дисперсионно-твердеющего сплава СДТС. Построена зависимость радиуса изгиба образцов подложек со структурами от температуры изохронного отжига и определены критические температуры и радиусы изгиба, приводящие к разрушению пленок после такого отжига, для различных толщин дисперсионно-твердеющего сплава СДТС. Получена зависимость коэрцитивной силы (КС) пленок от температуры изохронного отжига, которая при определенных условиях отжига превышает уровень, необходимый для применения этих пленок в магниторезистивных датчиках тока. Сделан вывод о том, что рост коэрцитивной силы КС после отжига связан с образованием выступов в дисперсионно-твердеющем сплаве СДТС.
\end{abstract}

Ключевые слова: магнетронное напыление, тонкие пленки, коэрцитивная сила, вакуумный отжиг.

\section{ВВЕДЕНИЕ}

В настоящее время различные составы являются основой для создания постоянных металлических магнитов в объемном исполнении. Материалы, используемые для создания постоянных магнитов в пленочном исполнении для микроэлектроники, должны быть согласованы с технологиями интегральных схем. При этом пленочные постоянные магниты применяют для планарного магнитного смещения магнитно мягких активных слоев магниторезисторов в

Зайончковский Вячеслав Станиславович, e-mail: zajonc4340@gmail.com кремниевых интегральных схемах бесконтактных датчиков тока и магниторезистивных датчиках магнитных дисковых накопителей информации. Это планарное смещение магниторезисторов необходимо для подавления части шума, связанной со скачками Баркгаузена. Ранее высококачественные пленочные магниты были реализованы на основе драгоценных металлов [1], что сильно увеличивает цену этих магнитов. Высокими магнитными свойствами обладают пленочные постоянные магниты на основе редкоземельных элементов [2], и на основе окиси кобальта или сплава Сo-Cr [3], одна-

Контент доступен под лицензией Creative Commons Attribution 4.0 License.

The content is available under Creative Commons Attribution 4.0 License. 
ко пленки всех этих составов обладают текстурой, приводящей к возникновению одноосной магнитной анизотропии типа «легкая ось», что исключает возможность их применения для создания планарного магнитного смещения. Применение пленочных постоянных магнитов на основе ферритов исключено, т. к. подложка для ферритов должна быть на основе окисных монокристаллов, либо эти пленочные ферритовые магниты должны быть реализованы на основе порошковой технологии с последующим спеканием. Это плохо согласуется с тем, что на этой же кремниевой подложке должна быть реализована монолитная микросхема для усиления сигнала магниторезистора и дальнейшей обработки этого сигнала. Поэтому круг магнитных материалов для создания постоянного пленочного магнита на кремниевой подложке может быть ограничен диффузионно-твердеющими и дисперсионно-твердеющими металлическими составами. Диффузионно-твердеющие составы на основе $\mathrm{Al}-\mathrm{Ni}-\mathrm{Cu}-\mathrm{Co}$ (ЮНДК или, как их называют за рубежом, alnico) базируются на дорогостоящих металлах (никеле и кобальте), и, кроме того, они обладают существенно большей твердостью, а значит и большей хрупкостью, чем дисперсионно-твердеющие составы (ДТС). Сплавы alnico механически обрабатываются только методами абразивной обработки - шлифовкой и полировкой [4], в то время как ДТС можно подвергать механической обработке резанием и давлением [5]. Эти сплавы являются деформируемыми при комнатных температурах, так как согласно данным [6], относительное удлинение перед разрушением $\delta$ может достигать величины (3:5) \%. Высокое содержание такого компонента как хром, более чем 20 \% по массе, придает им высокую коррозионную стойкость к окислению. Целью настоящей работы является разработка физико-технологических подходов создания гетероструктуры с пленочным постоянным магнитом на основе дисперсионно-твердеющего сплава с вектором намагниченности в плоскости кремниевой подложки.

\section{ЭКСПЕРИМЕНТАЛЬНАЯ ЧАСТЬ}

\section{Технология получения пленок}

Тонкие металлические пленки создавались магнетронным напылением на модифицированной установке вакуумного напыления УВН-71П3, в которой три термических источника были заменены на три планарных магнетрона. Предварительный вакуум в вакуумной камере со- здавался с помощью ротационного форвакуумного насоса 2НВР-5Д, а высокий вакуум - с помощью турбомолекулярного насоса НВТ-950. С целью обеспечения высокого качества атмосферы остаточных газов производился нагрев колпака вакуумной камеры и карусели с подложками. При этом давление остаточных газов в вакуумной камере перед напуском рабочего газа (сверхчистого аргона марки 5.5) было не выше $5 \cdot 10^{-4} \mathrm{~Pa}$. Температура подложек перед напылением адгезионного слоя (ванадия) составляла $200{ }^{\circ} \mathrm{C}$ и контролировалась с помощью терморезистора со скользящим контактом. В качестве мишеней использовали диски диаметром $90 \mathrm{~mm}$ из ванадия, меди и сплава $\mathrm{Fe}-\mathrm{Cr}-\mathrm{Co}$ (двух типов составов $22 \mathrm{X} 15 \mathrm{~K}$ и $25 \mathrm{X} 12 \mathrm{~K})$ с добавками, которые увеличивают склонность сплава $\mathrm{Fe}-\mathrm{Cr}-\mathrm{Co}$ к распаду пересыщенного раствора хрома в железе и кобальте при последующих термообработках (отжигах). Основной компонент этих составов - железо. Магнетроны функционировали с током плазмы до 3 А для медной, ванадиевой и, сначала, с такими же токами для магнетрона с мишенью ДТС состава 25X12K, но после ее расплавления, образцы получали только состава $22 \mathrm{X} 15 \mathrm{~K}$ с током плазмы магнетрона -2 А. Быстрая термическая обработка - БТО (rapid annealing), с целью достижения высококоэрцитивного состояния производилась в вакуумной «фотонной» печи при откачке диффузионным паромасляным насосом. При этом давление остаточных газов было не выше $10^{-3} \mathrm{~Pa}$, и важно, что вследствие откачки диффузионным паромасляным насосом атмосфера остаточных газов в «фотонной» печи имела восстановительный характер. В качестве источников излучения в «фотонной» печи использовали кварцевые галогенные лампы КГГ-220-1000-4 со световым потоком 26000 люменов, при цветовой температуре $3200 \mathrm{~K}$.

\section{Измерительная аппаратура}

Для измерения свойств тонких пленок применялись: конфокальная микроскопия с разрешением в плоскости изображения до $1 \mu \mathrm{m}$ и по вертикали - до $10 \mathrm{~nm}$, выполняемая с помощью конфокального микроскопа типа NanoFocus; рентгеновская дифрактометрия на дифрактометре ДРОН-2.0 (далее - дифрактометр). Снятие петель гистерезиса производилось в планарных полях (при намагничивании пленок в плоскости, как и для пленочных магнитов смещения магниторезистивных датчиков магнитного поля) на вибромагнитометре LAKESHORE-7407 кафедры магнетизма МГУ им. М. В. Ломоносова и установке для измерения меридиональ- 
ного магнитооптического эффекта Керра в ИРЭ им. В. А. Котельникова РАН [7]. Установка измерения эффекта Керра позволяет определять величину коэрцитивной силы образцов по намагниченности и коэффициент прямоугольности петли гистерезиса $\mathrm{Mr} / \mathrm{Ms}$ (отношение величины остаточной намагниченности $M r$ к величине намагниченности насыщения $M s)$, без определения абсолютного значения намагниченности насыщения. Состояние поверхности пленок определялось с помощью сканирующего электронного микроскопа JEOL JSM IT500 с увеличением до 17000x и атомно-силового микроскопа Solver P47H PRO, имеющего следующие параметры: минимальный шаг сканирования по оси z - 0.006 nm; минимальный шаг в плоскости $x / \mathrm{y}-0.012 \mathrm{~nm}$.

\section{Пленочные структуры}

В данной статье представлены результаты исследования структур, созданных на монокристаллических кремниевых подложках КЭФ-4.5 с ориентацией плоскости (100) и на монокристаллических кремниевых подложках КДБ-10 с

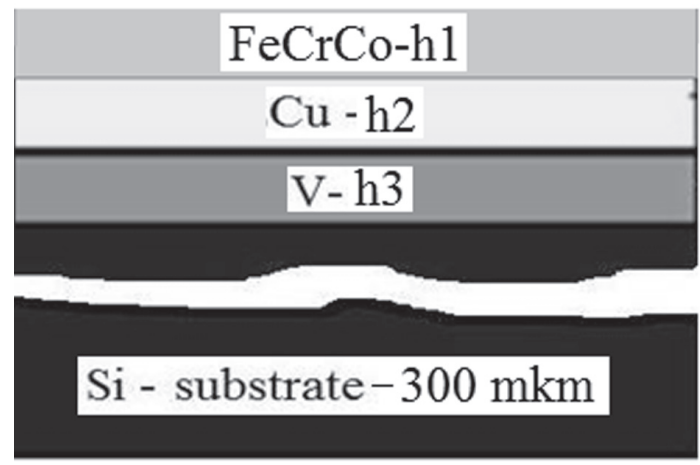

Рис. 1. Схема сечений структур, используемых в данной работе

[Fig. 1. Cross-section of the structures used in this work] ориентацией плоскости (111). Схема сечений этих структур представлена на рис. 1. Здесь h1 слой, основными компонентами которого являются железо, хром и кобальт; h2 - медный компенсационный слой; h3 - адгезионный ванадиевый слой. Величины высот слоев определялись на конфокальном микроскопе по величине ступеней, сформированных с помощью фотолитографии и последующего селективного травления. Содержание части основных компонентов в мишени (хрома и кобальта) для образцов структур № 3 составляло (22 и 15\%) соответственно, а для остальных структур (25 и 12\%) соответственно от всей массы сплава, что определялось с помощью портативного анализатора МетЭксперт (рентгеновского флюоресцентного спектрометра) [8]. Этот спектрометр имеет абсолютную погрешность измерения содержания компонента \pm $0.50 \%$, функционируя в режиме “никельсодержащие и нержавеющие стали” по элементам: титан, ванадий, хром, марганец, кобальт, никель, молибден и вольфрам, в диапазоне от 1.0 до 40.0\% по массе. Высоты напыленных слоев представлены в табл. 1.

В данном исследовании использовались мишени двух типов материалов. Для одного из них (22Cr15Co) характерны самые большие значения магнитных параметров, но сложная технология получения ВКС, а для другого (25Cr12Co) - простая технология, но достаточно низкие магнитные параметры.

Однослойная пленка ДТС на кремнии может быть напылена и быть цельной в широком диапазоне толщин (от 80 до $3800 \mathrm{~nm}$ ), но с ростом толщины СДТС сильнее проявляется деформация круглой монокристаллической пластины кремния в виде колпака. Для получения высококоэрцитивного состояния (BКС) необходимо

Таблица 1. Высота слоев исследуемых структур

[Table 1. Heights of the layers of the studied structures]

\begin{tabular}{|c|c|c|c|c|c|c|}
\hline \multirow{2}{*}{\multicolumn{2}{|c|}{$\begin{array}{c}\text { Характеристики структуры } \\
\text { [The characteristics of the structure] }\end{array}$}} & \multicolumn{5}{|c|}{$\begin{array}{l}\text { Номер структуры } \\
\text { [Structure number] }\end{array}$} \\
\hline & & No. 1 & No. 2 & No. 3 & No. 4 & No. 5 \\
\hline \multicolumn{2}{|c|}{$\begin{array}{c}\text { Состав мишени для хрома и кобальта } \\
\text { [The composition of the target for chro- } \\
\text { mium and cobalt] }\end{array}$} & 25Cr12Co & 25Cr12Co & $22 \mathrm{Cr} 15 \mathrm{Co}$ & $25 \mathrm{Cr} 12 \mathrm{Co}$ & 25Cr12Co \\
\hline \multirow{3}{*}{$\begin{array}{c}\text { Высота слоев } \\
\text { [Heights of the layers, nm] }\end{array}$} & h1 & 1000 & 80 & 200 & 1800 & 3600 \\
\hline & $\mathrm{h} 2$ & - & 120 & 400 & 1900 & 3800 \\
\hline & h3 & 110 & 110 & 70 & 110 & 110 \\
\hline \multicolumn{2}{|c|}{$\begin{array}{c}\text { Тип подложки и ориентация } \\
\text { [The type of substrate and orientation } \\
\text { planes] }\end{array}$} & \multicolumn{3}{|c|}{ КЭФ-4.5 (100) } & \multicolumn{2}{|c|}{ КДБ-10 (100) } \\
\hline
\end{tabular}


проводить отжиг для проведения спинодального распада пересыщенного твердого раствора хрома в железе, при этом часто имеет место разрушение слоя ДТС с отрывом от нижележащих слоев, (рис. 2). На конфокальном снимке (верхняя часть этого рисунка) представлена картина разрушения подложки кремния с ориентацией плоскости (100) слоем состава Fe-Cr-Co (структура № 1). СДТС толщиной $1 \mu \mathrm{m}$ разрушает кремниевую подложку на глубину до $10 \mu \mathrm{m}$. На этом снимке хорошо видны области с прямоугольной симметрией, что связано с ориентацией плоскости, используемой кремниевой подложки (в данном случае КЭФ-4.5). На нижней части этого рисунка представлено сечение поверхности пластины кремния с пленкой $\mathrm{Fe}-\mathrm{Cr}-\mathrm{Co}$ вдоль линии АВ (длиной $0.85 \mathrm{~mm}$ ). На правой части этого рисунка приведена топограмма высот (квази-3D изображение) части поверхности разрушенной монокристаллической подложки кремния. Согласно этой части рисунка слой ДТС толщиной $1 \mu \mathrm{m}$ повреждает кремниевую подложку на глубину до $10 \mu \mathrm{m}$. При этом простого отслоения пленки от подложки не наблюдается вследствие высокой адгезии пленки к подложке. Так содержание хрома в мишени, и, ожидаемо на подложке, более 20 \% по массе. Указанное выше разрушение подложки пленкой сплава $\mathrm{Fe}-\mathrm{Cr}-\mathrm{Co}$ после отжига можно связать с модуляцией параметра кристаллической решетки этого сплава (разбиением на фазы) [9], что вызывает большие механические напряжения в нижележащих слоях.

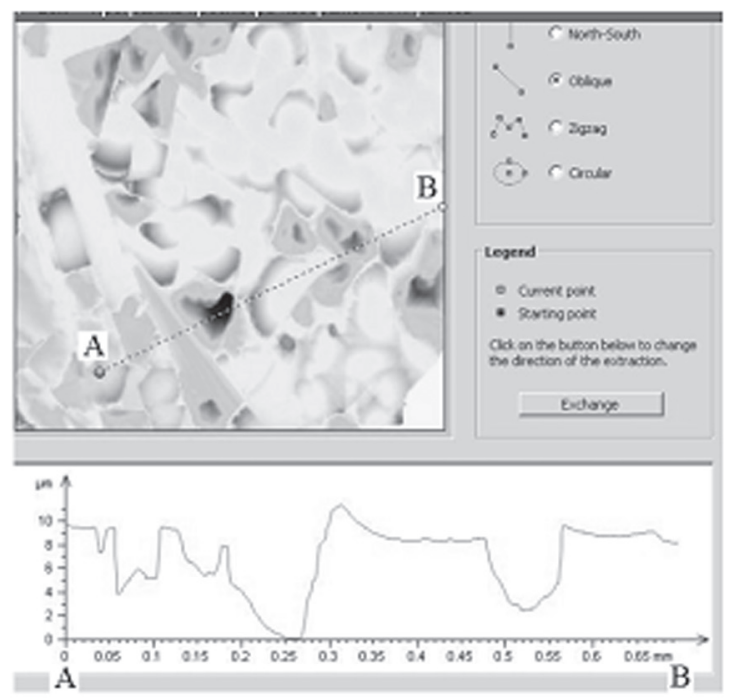

Для сохранения целостности структуры в состав пленки был включен компенсирующий слой - слой меди, которая может деформироваться в больших пределах, так как имеет большое относительное удлинение $\delta$ до разрыва $\left(\delta_{\max \mathrm{Cu}}=45 \%\right)[10]$. Но в связи с тем, что этот слой имеет плохую адгезию к монокристаллическому кремнию, то в структуру пленки был добавлен адгезионный слой - слой ванадия. Слой ванадия плохо приспособлен для компенсации модуляции параметра кристаллической решетки СДТС ( $\left.\delta_{\max \mathrm{V}}=17 \%\right)$ [11], но этот слой проявляет не только высокие адгезионные свойства к монокристаллическому кремнию, но и хорошо совместим со слоем меди [12]. Это связано с тем, что ванадий не образует интерметаллидов с медью. При этом слой ванадия является диффузионным барьером для меди.

Для проведения измерений магнитных свойств и уровня деформации подложек применялись образцы, вырезанные из подложек монокристаллического кремния толщиной $300 \pm 15 \mu \mathrm{m}$. Эти образцы представляли собой (в плане) квадраты со стороной $4 \mathrm{~mm}$ - для измерений на вибромагнетометре и установке измерения магнитооптического эффекта Керра, ориентация плоскости односторонне полированных подложек КЭФ-4.5 - (100). Для рентгеновских измерений радиуса изгиба структур использовались образцы - (в плане) квадраты со стороной, равной $15 \mathrm{~mm}$ (ориентация плоскости двухсторонне полированных подложек КДБ-10 (111)). Такие разные ориентации подложек ис-

Рис. 2. Конфокальный снимок поверхности структуры $\mathrm{Si} / \mathrm{V} / \mathrm{Fe}-\mathrm{Cr}-\mathrm{Co}$, разрушенной в результате фотонного отжига с целью достижения ВКС

[Fig. 2. Confocal image of the surface of the $\mathrm{Si} / \mathrm{V} / \mathrm{Fe}-\mathrm{Cr}-\mathrm{Co}$ structure destroyed by annealing in a $650{ }^{\circ} \mathrm{C} / 60 \mathrm{~s}$ "photon" furnace conducted to achieve a highly coercive state] 
пользовались в связи с тем, что малые образцы формировались скрайбированием и последующим разламыванием по плоскостям спайности, что возможно для пластин с ориентацией плоскости (100). Большие образцы, на основе полированных с двух сторон подложек с ориентацией (111), формировались разрезом исходной полупроводниковой подложки на всю толщину подложки, так как корректное скрайбирование и разламывание для них невозможно. Для определения величины отношения толщины слоя меди к толщине слоя сплава $\mathrm{Fe}-\mathrm{Cr}-\mathrm{Co}$, при котором пленка оставалась целой после отжига, были проведены многочисленные эксперименты. Эти эксперименты показали, что для сохранения в целостности СДТС минимально необходимая толщина слоя меди должна быть не меньше, чем толщина СДТС. При получении объемных магнитов на основе большинства марок ДТС необходимо с помощью высокотемпературной гомогенизации и последующей закалки не допустить появление нежелательных фаз $\gamma$ и $\sigma$, которые возникают в процессе остывании слитков (на воздухе) при температурах свыше $800{ }^{\circ} \mathrm{C}$ [9]. Таковым является сплав с номинальным составом по хрому и кобальту (22Cr15Co), в то время как для состава (25Cr15Co) такое жесткое требование (требование проведения закалки зависит от скорости охлаждения сплава после литья до комнатных температур) может не выдвигаться [6]. В нашей технологии пленки напылялись магнетронным способом, при этом температура подложек не превышала $200{ }^{\circ} \mathrm{C}$, что не достаточно для плавления СДТС (см. далее).

Так как пленочные постоянные магниты создаются на кремниевой подложке, являющейся основой монолитной интегральной схемы, то одним из важнейших параметров подложки, на которой будут выполняться процессы фотолитографии, является величина радиуса изгиба подложки. Измерения радиуса изгиба образцов, квадратных в плане, производились на двухкристальном рентгеновском дифрактометре ДРОН-2.0 в геометрии на отражение [13]. При этом исследовались две серии образцов двух типов структур (№ 4 и № 5), вырезанных из одной подложки кремния с ориентацией поверхности (111) и полированной с двух сторон, с пленками, содержащими слои ДТС до и после 60-секундного отжига. Эти две серии образцов пластинок кремния (далее - образцы) имели (в плане) размеры $15 \times 15 \mathrm{~mm}^{2}$, при этом слои ДТС имели (в плане) размеры $12 \times 12 \mathrm{~mm}^{2}$, и центры обоих квадратов совпадали.

\section{РЕЗУЛЬТАТЫ И ИХ ОБСУЖДЕНИЕ}

Для получения больших полей смещения на значительных расстояниях от пленочного магнита требуются пленки с ферромагнитными слоями, имеющими большую намагниченность и большую толщину. С целью опробования компенсационной способности медных слоев были получены пленки с СДТС состава 25Cr12Co (не требующего сложной термообработки в объемном исполнении) разной толщины, но с одинаковым отношением толщины компенсационного слоя к толщине СТС. Показателем уровня механических напряжений в структурах был выбран радиус изгиба образцов $15 \times 15 \times 0.3 \mathrm{~mm}$, содержащих все три слоя: адгезионный слой ванадия, компенсационный слой меди и слой ДТС на кремниевой подложке КДБ-10 с ориентацией поверхности (111). Эти подложки были полированы с двух сторон, при этом был невелик вклад в изгиб подложки от нарушенного слоя обратной стороны кремниевой пластины, на которую наносились указанные выше три слоя. При этом получались узкие пики рентгеновских лучей, отражаемых от лицевой высокосовершенной поверхности монокристаллического кремния - полуширина кривой качания составляла 9.63 arcs.

Радиус изгиба образцов подложек измерялся до и после 60-секундного «фотонного» отжига, при падении рентгеновского луча на сторону образца, имеющую высокосовершенную полированную поверхность (лицевую поверхность). Образцы без пленок имели радиус кривизны 240 $\mathrm{m}$, при этом наблюдалась вогнутость со стороны падения рентгеновского луча, что связано с существованием нарушенного слоя на обратной стороне подложки. Однослойная пленка ванадия толщиной 110 nm, нанесенная на поверхность обратной стороны образца, уменьшала радиус кривизны до 229 m. Знак деформации в этом случае не менялся. Пленка ванадия была сжата. Нанесение слоев меди и СДТС Fe-Cr-Co приводило к тому, что у образцов возникала выпуклость со стороны падения рентгеновского луча, соответственно пленки, содержащие слой ДТС, были растянуты. На рис. 3 представлены зависимости радиуса кривизны образцов до и после одноступенчатого 60-секундного отжига в «фотонной» печи на ВКС.

Этот график показывает снижение радиуса кривизны исследованных образцов, что может быть связано с процессами как рекристаллизации, так и спинодального распада пересыщенного твердого раствора. Критический радиус изгиба образцов достигал уровня $6 \mathrm{~m}$ и менее, после 


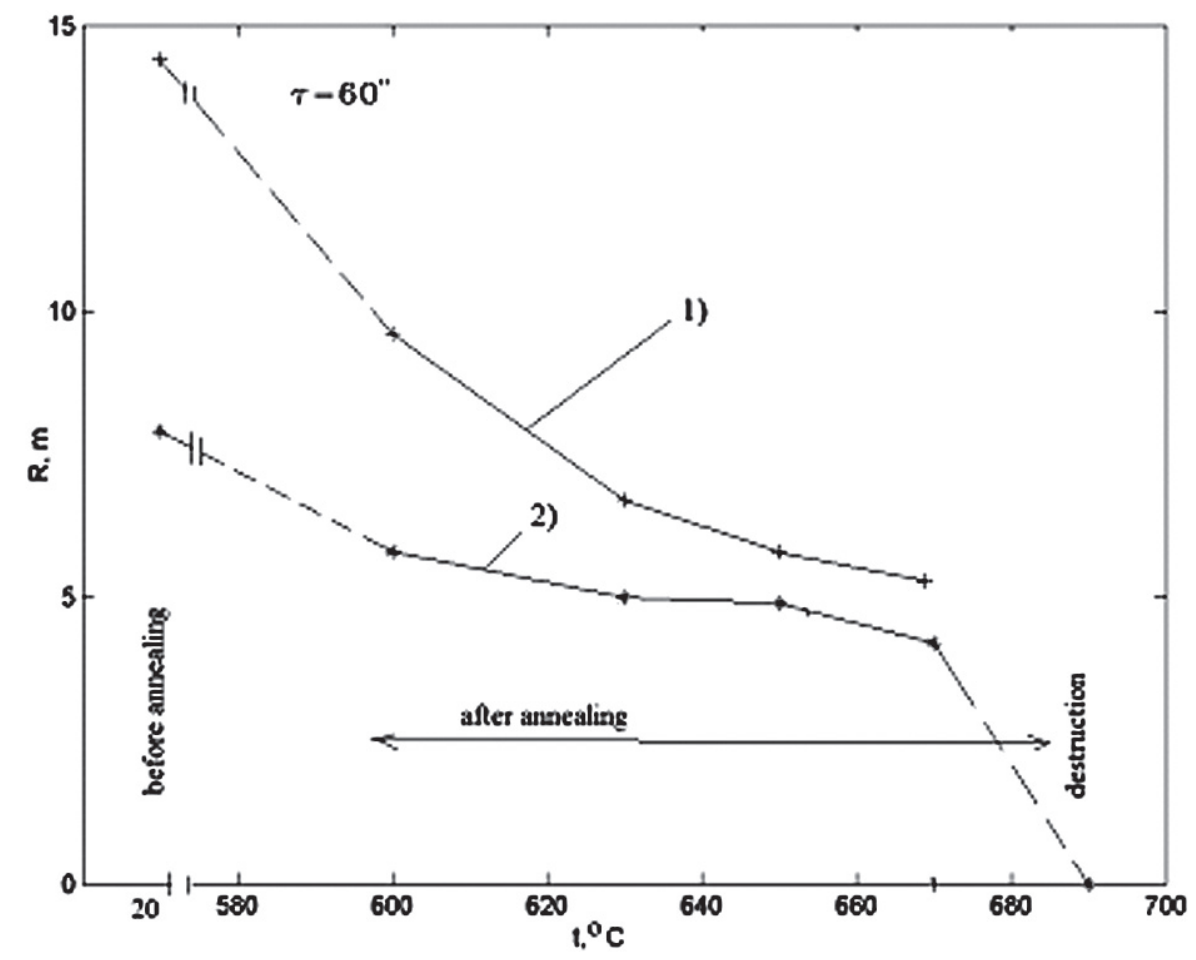

Рис. 3. Зависимость радиуса кривизны образцов структур с ДТС от изохронного одноступенчатого фотонного отжига длительностью 60 s. Кривая 1 - структура № 4, (табл. 1); 2 - структура № 5, (табл. 1). Состав хрома и кобальта - 25Cr12Co

[Fig. 3. Dependence of the radius of curvature of two samples of structures with DTS on isochronous singlestage annealing in a "photonic" furnace with a duration of 60 seconds. Curve 1 - structure No. 4, (table. 1); 2 structure No. 5, (tab. 1). Composition of chromium and cobalt - 25Cr12Co]

чего наблюдалось разрушение и пленки и поверхности образца кремниевой подложки. Оценить уровень механических напряжений при изгибе не представлялось возможным вследствие неприменимости классической формулы Стоуни $[12,13]$, так как пленка содержит три разнородных слоя, и эти слои могут испытывать пластическую деформацию и фазовые переходы.

\section{Исследование коэрцитивной силы}

Петля гистерезиса, как главная магнитная характеристика магнитнотвердых материалов, снималась для двух составов, указанных выше, до и после одноступенчатого отжига. Петля гистерезиса для структуры № $1(\mathrm{~h} 1=80 \mathrm{~nm})$ снята на вибромагнитометре до и после 60-секундного «фотонного» отжига при температуре $650{ }^{\circ} \mathrm{C}$ и представлена на рис. 4 и 5 соответственно.

Прямоугольность петли гистерезиса до отжига свидетельствует о том, что СДТС является однородным (однофазным) - коэрцитивная сила $-79 \cdot 80 \mathrm{~A} / \mathrm{m}$. Тот же СДТС, но уже после отжига, представлен на рис. 5 . Он имеет наклонную петлю гистерезиса, что свидетельствует о том, что магнитных фаз больше, чем одна, при этом коэрцитивная сила возросла до $382 \cdot 80 \mathrm{~A} / \mathrm{m}$.
Экспрессное измерение величины коэрцитивной силы серии пленок со структурой № 3 производилось на установке измерения магнитооптического эффекта Керра. Ниже (рис. 6 и 7) приведены примеры нормированных петель гистерезиса для образцов структуры № 3 до отжига (рис. 6), а на рис. 7 после 60-секундного отжига при температуре $670{ }^{\circ} \mathrm{C}$.

Сравнение вида петель гистерезиса показывает, что в результате одноступенчатого отжига значительно (более чем в 2 раза) возрастает величина коэрцитивной силы пленок для тонких пленок (80 nm для состава 25Cr12Со и 200 $\mathrm{nm}$ для состава 22Cr15Co). При этом имеет место уменьшение коэффициента прямоугольности петли гистерезиса $\mathrm{Mr} / \mathrm{Ms}$ (уменьшается отношение остаточной намагниченности к величине намагниченности насыщения). Зависимости величины коэрцитивной силы от температуры одноступенчатого 60-секундного отжига для двух использованных составов, и, к сожалению, с разными толщинами СДТС, приведены на рис. 8.

Из вида данных (рис. 5) и (рис. 7) следует, что тонкие пленки (с высотой СДТС $80 \mathrm{~nm}$ - состава $25 \mathrm{Cr} 15$ Со и с высотой $200 \mathrm{~nm}$ - состава 22Cr15Co) 


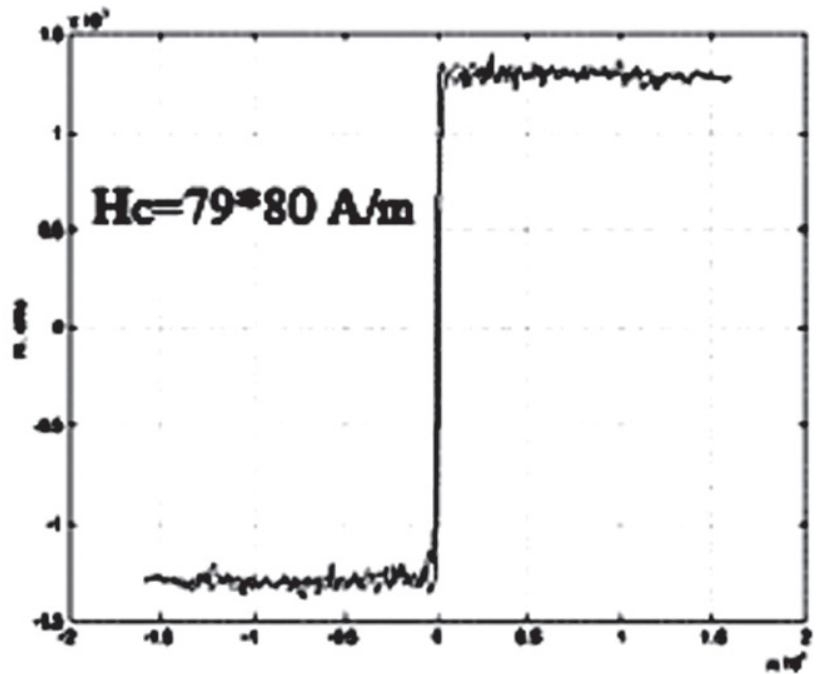

Fin planerod, Asm

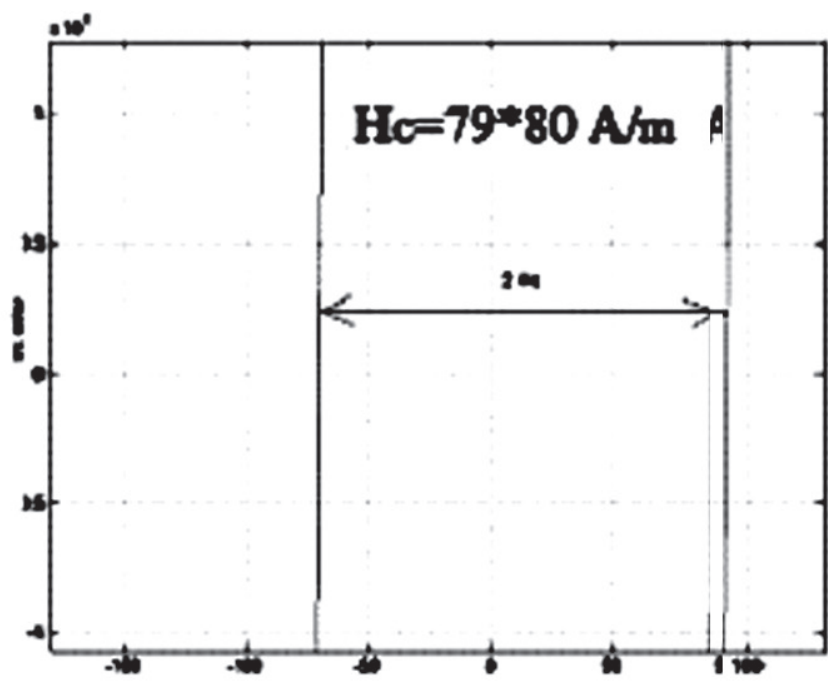

In pleneron, Am

$a$

$b$

Рис. 4. Петля гистерезиса структуры № 1 до фотонного отжига: $a$ - полная петля, $b$ - после растяжки по двум осям. Состав хрома и кобальта -25Cr12Co

[Fig. 4. Hysteresis loop of structure No. 1 before annealing: $a$ - full loop, $b$ - part of the loop after stretching along two axes. Composition of chromium and cobalt - 25Cr12Co]

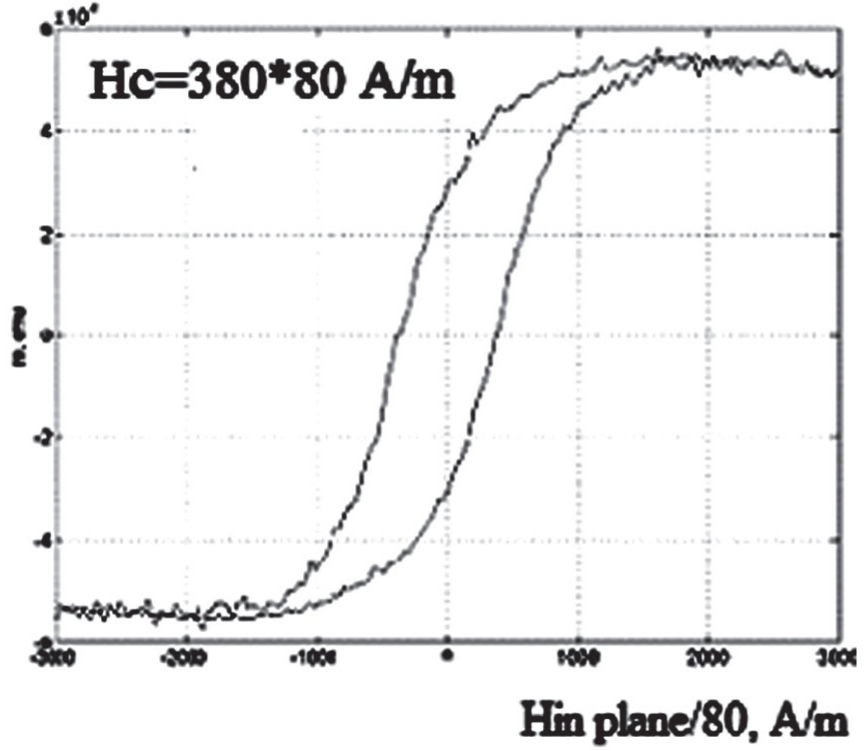

$a$

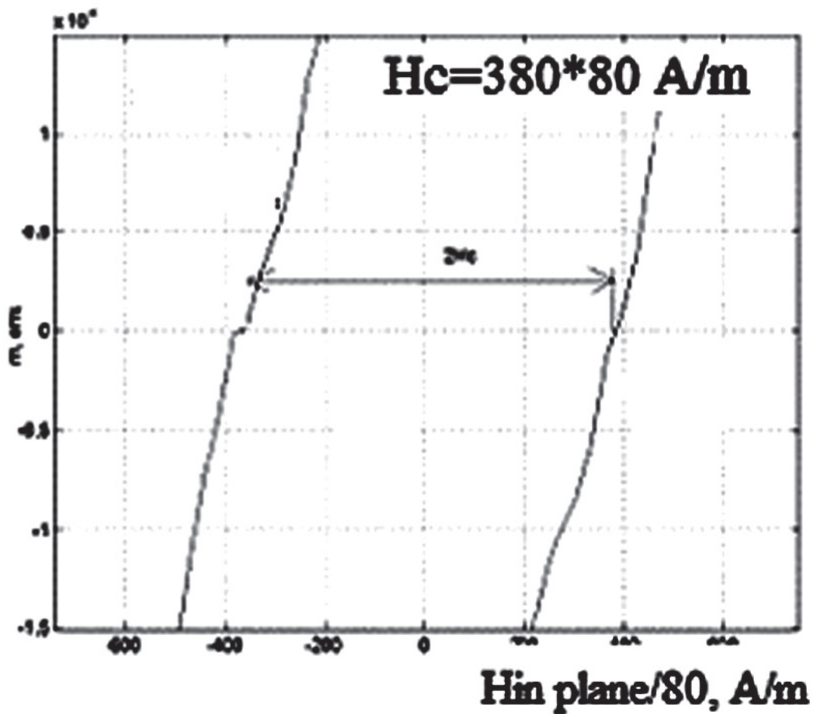

$b$

Рис. 5. Петля гистерезиса структуры № 1 после фотонного отжига 650 드으 s: $a$ - полная петля, $b$ - часть петли после растяжки по двум осям. Состав хрома и кобальта - 25Cr12Co

[Fig. 5. Hysteresis loop of structure No. 1 after annealing $60 \mathrm{~s}$ in a "photonic" furnace at $t=650{ }^{\circ} \mathrm{C}: a-$ full loop, $b$ - part of the loop after stretching along two axes. Composition of chromium and cobalt - 25Cr12Co] 


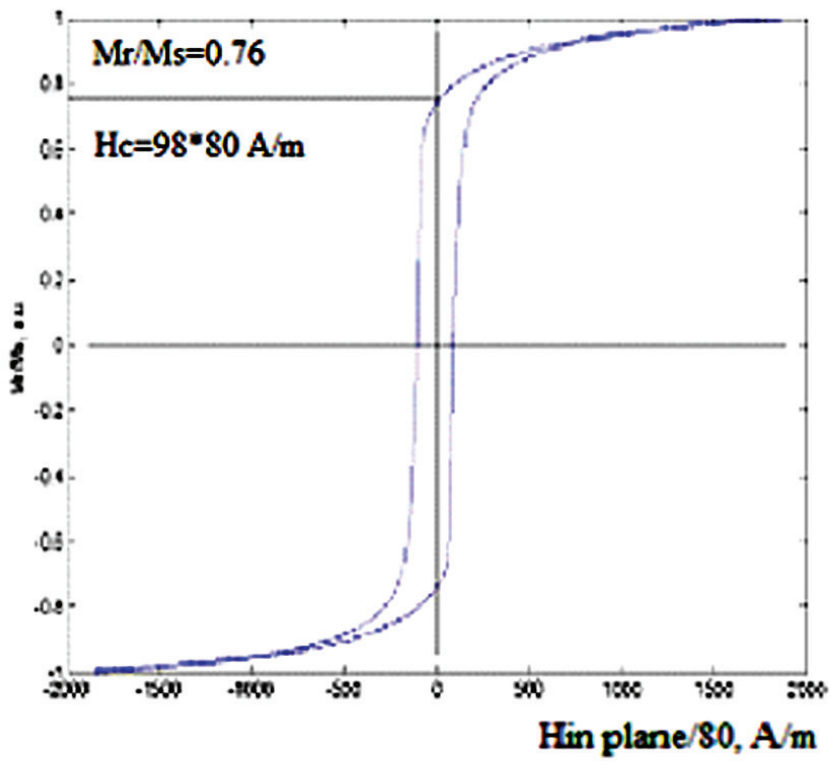

$a$

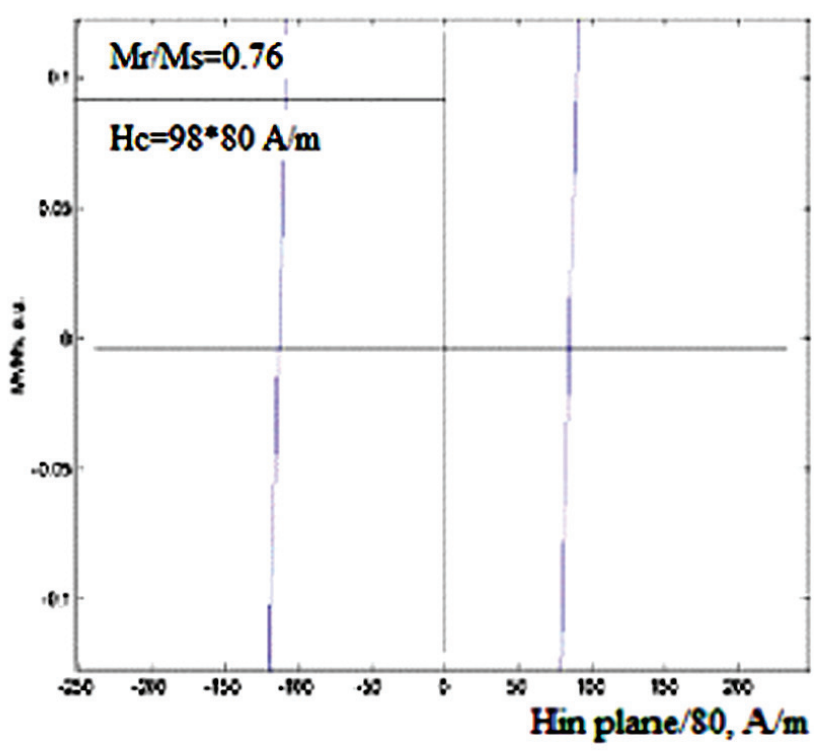

$b$

Рис. 6. Петля гистерезиса структуры № 3 до фотонного отжига: $a$ - полная петля, $b$ - часть петли после растяжки по двум осям. Состав хрома и кобальта - 22Cr15Co

[Fig. 6. Hysteresis loop of structure No. 3 before annealing: $a$ - full loop, $b$ - part of the loop after stretching along two axes. Composition of chromium and cobalt-22Cr15Co]

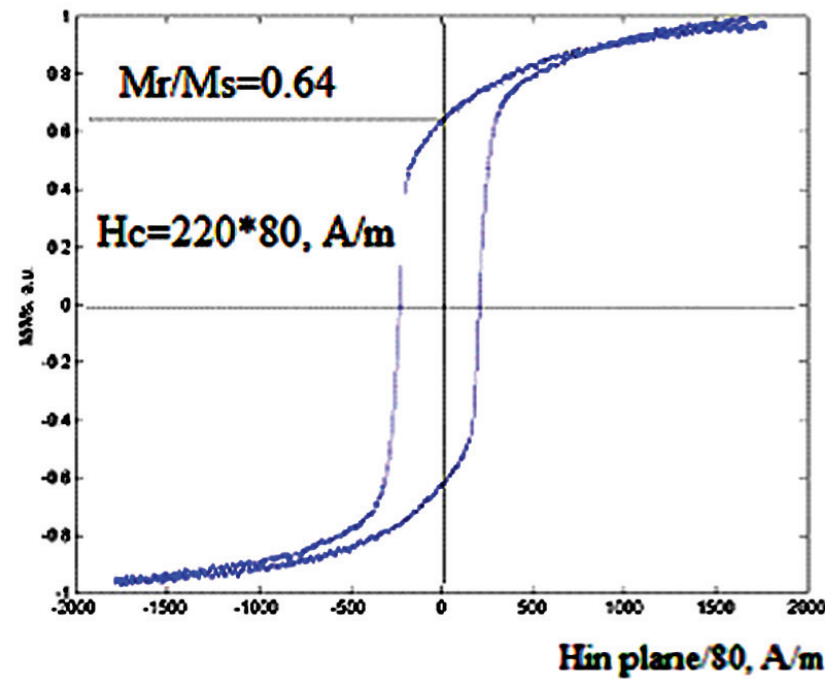

$a$

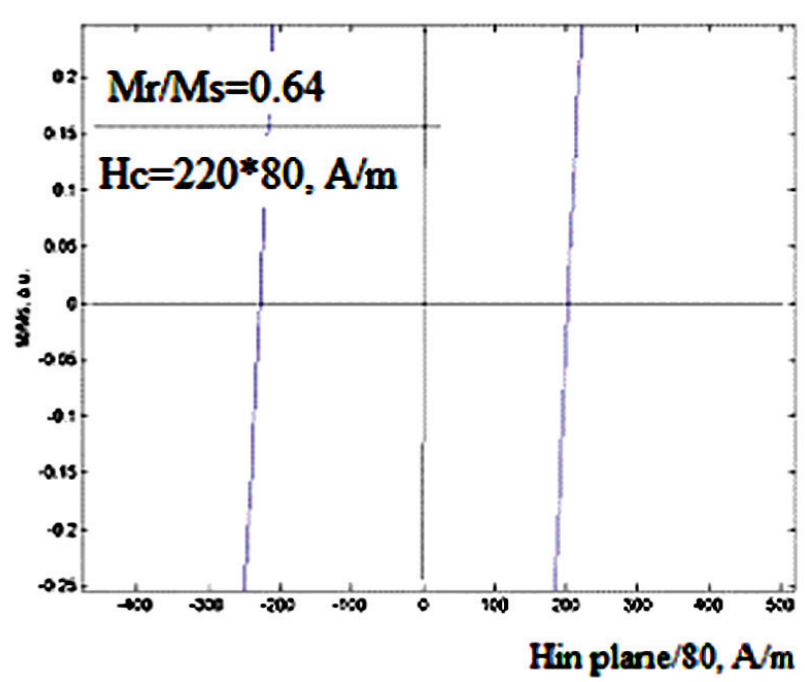

$b$

Рис. 7. Петля гистерезиса структуры № 3 после $60 \mathrm{~s}$ фотонного отжига при $t=670{ }^{\circ} \mathrm{C}: a-$ полная петля, $b$ - часть петли после растяжки по двум осям. Состав хрома и кобальта - 22Cr15Сo

[Fig. 7. Hysteresis loop of structure No. 3 after $60 \mathrm{~s}$ annealing in a "photonic" furnace at $t=670{ }^{\circ} \mathrm{C}: a-\mathrm{full}$ loop, $b$ - part of the loop after stretching along two axes. The composition of chromium and cobalt-

22Cr15Co] 


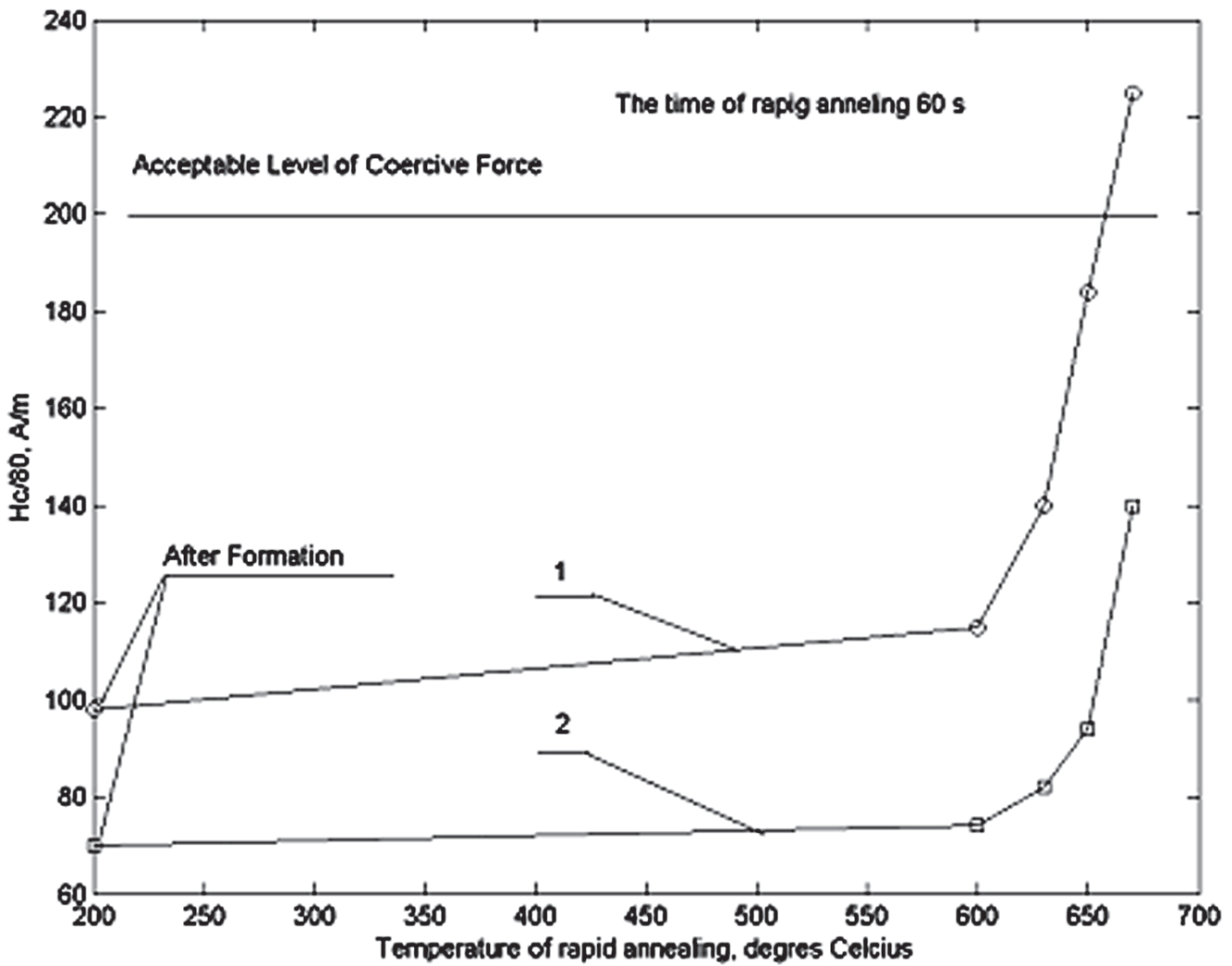

Рис. 8. Температурная зависимость коэрцитивной силы образцов со структурой № 3 (кривая 1) и № 5 (кривая 2) при времени быстрого отжига $60 \mathrm{~s}$

[Fig. 8. Temperature dependence of coercive force of samples with structures No. 3 (curve 1) and No. 5 (curve 2) at rapid annealing time $60 \mathrm{~s}]$

имеют значительные величины коэрцитивной силы и могут быть применены уже сейчас для создания пленочных постоянных магнитов. Этого нельзя сказать о толстых пленках состава 25Cr12Co, коэрцитивная сила которых значительно ниже, требуемого уровня.

\section{Рельеф поверхности}

СДТС, получаемые после магнетронного напыления, имеют рельеф поверхности (определенный с помощью атомно-силового микроскопа), как наследованный от рельефа кремниевой подложки с тем же характерным перепадом высот и длиной повторения выступов и впадин, рис. 9. Полированная сторона кремниевой подложки (доступной нам), предназначенная для изготовления интегральных схем средней степени интеграции, имеет перепад высот не более 60 nm. Перепад высот на профилограмме (рис. 9b), на котором представлен профиль половины сечения поверхности структуры № 3 по линии 1 , укладывается в диапазон $40 \mathrm{~nm}$.

На рис. 10 показан атомно-силовой скан высот поверхности структуры № 3 после 60-секундного отжига при температуре $650{ }^{\circ} \mathrm{C}$. Часть профиля, примерно половина сечения поверхности по линии 1 - рис. 10b, свидетельствует, что на поверхности пленки появились пики (выступы) с высотой до $90 \mathrm{~nm}$ над средним уровнем выступов при диаметре выступа по основанию - примерно $1 \mu \mathrm{m}$. По градациям серого шкалы высот некоторые из пиков достигают высоты почти до $190 \mathrm{~nm}$.

Для анализа происхождения этих выступов были сделаны электронно-микроскопические снимки в отраженных электронах. Эти снимки (рис. 11) показали, что даже при отжиге $600{ }^{\circ} \mathrm{C} / 60 \mathrm{~s}$ начинают формироваться выступы на поверхности пленки, (рис. 11a), которые при температуре отжига $670{ }^{\circ} \mathrm{C}$ в некоторых «дефектных» местах плавятся, а при остывании кристаллизуются с образованием дендритов (рис. 11b). Плавление пленок малой толщины при температурах существенно более низких, чем температура плавления объемных образцов, наблюдалось ранее в тонких пленках меди в работах $[14,15]$.

Таким образом, можно предположить, что механизм роста коэрцитивной силы тонких пленок (с толщиной СДТС $200 \mathrm{~nm}$ и менее) может быть связан с образованием выступов, т. к. пе- 


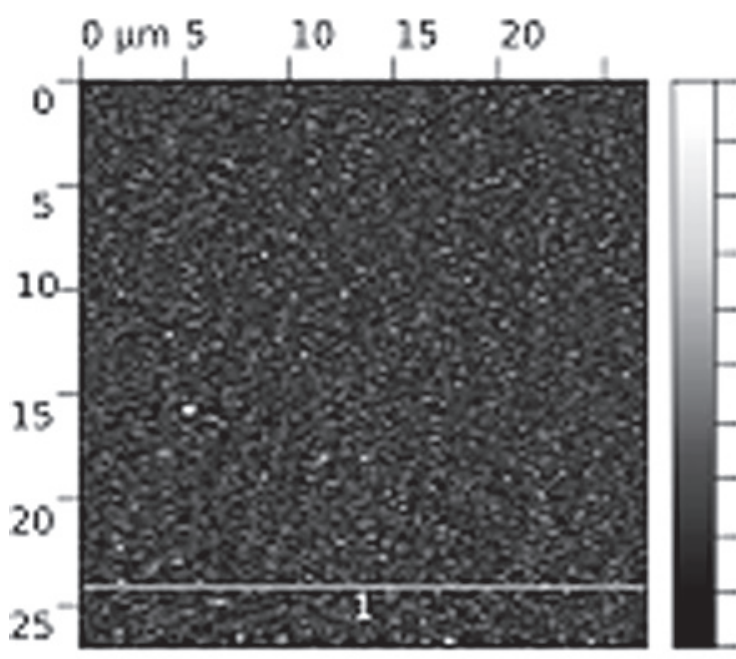

$a$

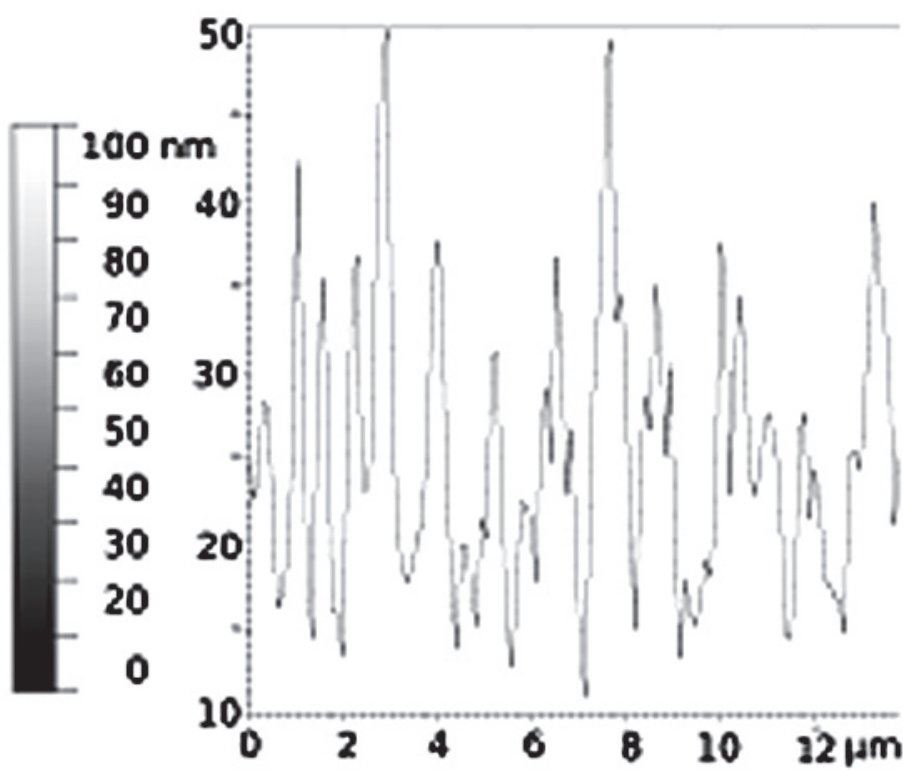

$b$

Рис. 9. Атомно-силовой скан поверхности образцов структуры № 3 (табл. 1) до отжига: $a$ - карта уровней высот; $b$ - часть профиля сечения поверхности вдоль линии 1

[Fig. 9. Atomic force scan of the surface of samples of structure No. 3, (table 1) before annealing: $a$ - map of elevation levels; $b$ - part of the surface cross-section profile along line 1]

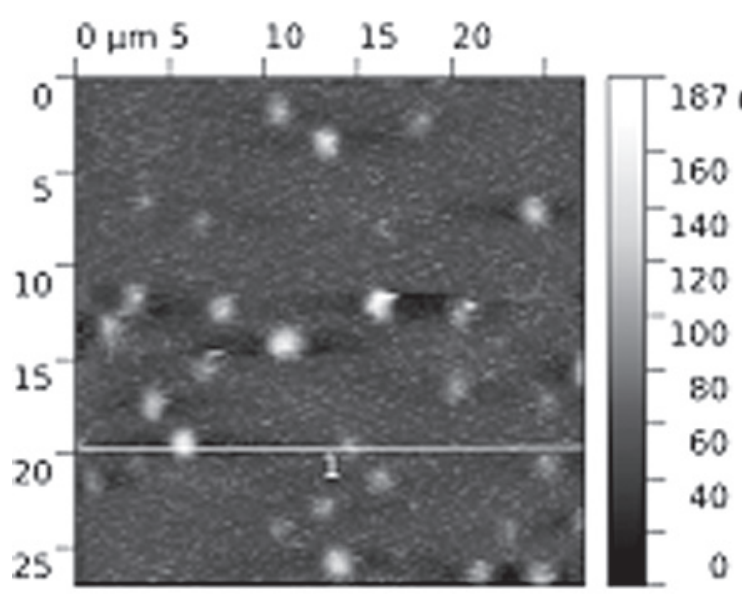

$a$

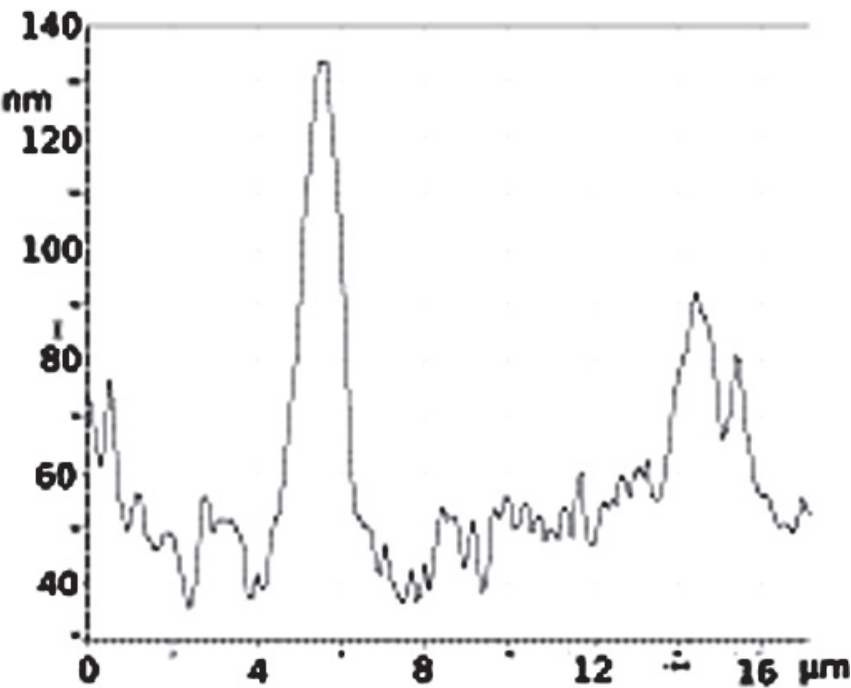

$b$

Рис. 10. Атомно-силовой скан поверхности образцов структуры № 3, (табл. 1), после отжига $650{ }^{\circ} \mathrm{C} / 60$ $\mathrm{s}: a$ - карта уровней высот; $b$ - профиль сечения поверхности вдоль линии 1

[Fig. 10. Atomic force scan of the surface of samples of structure No. 3, (table 1), after annealing $650{ }^{\circ} \mathrm{C} / 60 \mathrm{~s}$ : $a$ - map of elevation levels; $b$ - part of the surface cross-section profile along line 1] 


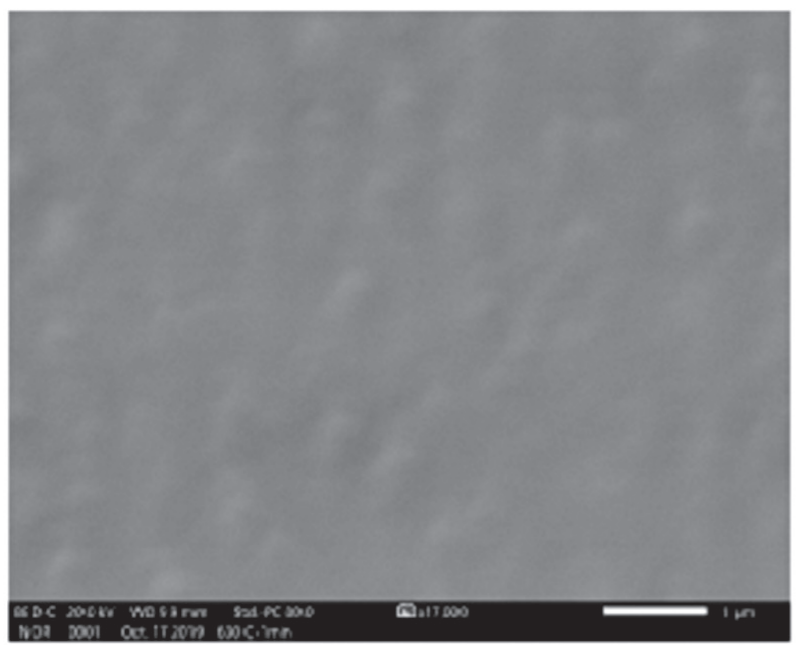

$a$

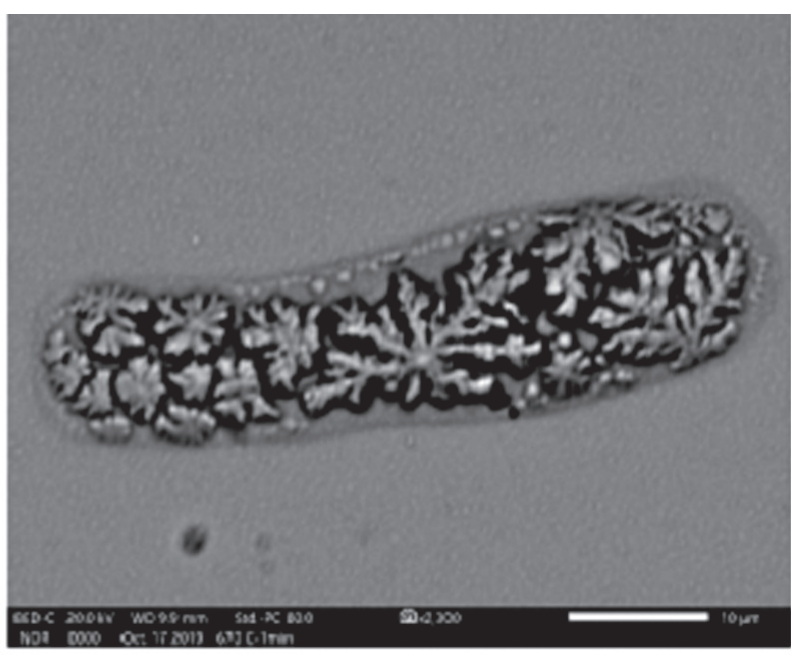

$b$

Рис. 11. РЭМ-микрофотографии в отраженных электронах (структура № 3) после отжига: $a$ - при 630 ${ }^{\circ} \mathrm{C} / 60 \mathrm{~s}$ (увеличение $17000 \mathrm{x}$ ); $b$ - при $670{ }^{\circ} \mathrm{C} / 60 \mathrm{~s}$ (увеличение 2300x)

[Fig. 11. SEM-micrrographs in reflected electrons (structure No. 3) after annealing: $a-$ at $630{ }^{\circ} \mathrm{C} / 60 \mathrm{~s}$ (17000x magnification); $b$ - at $670{ }^{\circ} \mathrm{C} / 60 \mathrm{~s}$ (2300x magnification)]

репад высот является энергетическим барьером, тормозящим движение доменных стенок. Для относительно толстых пленок ( $11 \geqslant 1 \mu \mathrm{m})$ одноступенчатый отжиг при использованных в данном исследовании температурах не дает существенного роста коэрцитивной силы $(H \mathrm{c}=140 \cdot 80 \mathrm{~A} / \mathrm{m})$, и необходимо провести дополнительные работы для выведения коэрцитивной силы толстых пленок на приемлемый уровень.

\section{ВЫВОДЫ}

1. Впервые создана гетероструктура пленочного постоянного магнита на кремниевой монокристаллической подложке, содержащей магнитный слой дисперсионно-твердеющего сплава $\mathrm{Fe}-\mathrm{Cr}-\mathrm{Co}$.

2. Определены оптимальные режимы высоковакуумного отжига, создающего высококоэрцитивное состояние ферромагнитного слоя дисперсионно-твердеющего сплава пленки без ее разрушения.

3. Установлено, что рост коэрцитивной силы пленок, содержащих СДТС, при малых толщинах СДТС согласован с формированием высокого уровня механических напряжений в этих слоях при отжиге в диапазоне температур $(600 \div 670){ }^{\circ} \mathrm{C}$.

\section{БЛАГОДАРНОСТИ}

Для данных исследований конфокальный микроскоп NanoFocus был любезно предоставлен руководством предприятия Растр-Технология, г. Обнинск. Магнитные измерения проведены с ис- пользованием оборудования, приобретенного за счет средств Программы развития Московского университета. Авторы благодарны сотрудникам ЦКП “Материаловедение и металлургия” МИСиС за РЭМ-снимки поверхности пленок.

\section{КОНФЛИКТ ИНТЕРЕСОВ}

Авторы декларируют отсутствие явных и потенциальных конфликтов интересов связанных с публикацией настоящей статьи.

\section{СПИСОК ЛИТЕРАТУРЫ}

1. Masahiro Kitada, Yoshihisa Kamo, Hideo Tanabe. Magnetoresistive thinыfilm sensor with permanent magnet biasing film// Journal of Applied Physics, 1985, v. 58(4), pp. 1667-1670. DOI: https://doi.org/ $10.1063 / 1.336058$

2. Leo K. E. B. Serrona, Sugimura A., Fujisaki R., Okuda T., Adachi N., Ohsato H., Sakamoto I., Nakanishi A. Magnetic and structural properties of NdFeB thin film prepared by step annealing // Materials Science and Engineering B, 2003,v. 97(1), pp. 59-63. DOI: https://doi.org/10.1016/s0921-5107(02)00401-4

3. Хлопов Б. В., Самойлова В. С., Юрьев И. А. Изменение состояния тонкопленочных слоев магнитных материалов, применяемых в системах внешней памяти жестких магнитных дисков // T-Comm: Телекоммуникация и транспорт, 2015, т. 9(12), с. 5-11.

4. Коноплёв Ю. В., Изгородин А. К. Структурообразование, свойства и применение горячедеформированных сплавов ЮНДК и ЮНДКТ. Режим доступа: https://cyberleninka.ru/article/n/strukturoobrazovanie-svoystva-i-primenenie-gory- 
achedeformirovannyh-splavov-yundk-i-yundkt (дата обращения: 24.10.2019).

5. Kaneko H., Homma M., Nakamura K. New ductile permanent magnet of Fe-Cr-Co system // AJP Conference Proceedings. 1972, no. 5, pp. 1088-1092. DOI: https://doi.org/10.1063/1.2953814

6. ГОСТ 24897-81. Материалы магнитотвердые деформируемые. Solid magnetic deformed materials. Marks. М.: Издательство стандартов, 1981, 21 с.

7. Овсянников Г. А., Петржик А. М., Борисенко И. В., Климов А. А., Игнатов Ю. А., Демидов В. В., Никитов С. А. Магнитно-транспортные характеристики напряженных эпитаксиальных манганитных пленок $\mathrm{La}_{0.7} \mathrm{Sr}_{0.3} \mathrm{MnO}_{3} / /$ ЖЭТФ, 2009, т. 135(1), c. $56-64$.

8. Сайт компании ООО «ГЕО-НДТ». Режим доступа: https:/www.geo-ndt.ru/pribor-6855-rentgenoflyorescentnii-analizator-metekspert.htm (дата обращения: 20.10.2019)

9. Кекало И. Б., Самарин Б. А. Физическое металловедение прецизионных сплавов. Сплавы с особыми магнитными свойствами. М.: Металлургия, 1989, $496 \mathrm{c}$.

10. Справочник по иветным металлам. Режим доступа: https://ibmetal.ru/index.htm (дата обращения: 24.10.2019)

11. Всё о металлургии. Режим доступа: http:// metal-archive.ru/vanadiy/955-mehanicheskie- svoystva-vanadiya.html (дата обращения: 24.10.2019)

12. Громов Д. Г. Металлизация ультрабольщих интегральных схем. Учебное пособие / Д. Г. Громов, А. И. Мочалов, А. Д Сулимин, В. И. Шевяков. М.: БИНОМ, 2012. 277 с.

13. Прохоров И. А., Захаров Б. Г. Рентгенодифракционные исследования особенностей релаксации и распределения макронапряжений в эпитаксиальных структурах // Поверхность. Рентгеновские, синхротронные и нейтронные исследования, 1999, № 2 , с. 106-109.

14. Stouney G. S. The Tension of Metallic Films Deposited by Electrolysis // Proceedings of the Royal Society A: Mathematical, Physical and Engineering Sciences, 1909, v. 82(553), pp. 172-175. DOI: https://doi. org/10.1098/rspa.1909.0021

15. Добрынин В. А. О применимости формулы Стоуни для расчета механических напряжений в толстых пленках и покрытиях // Письма в ЖТФ, 1997, т. 23, № 18, с. 32-36.

16. Громов Д. Г. Размерный эффект плавления в пленочных структурах наноэлектроники // Нанотехнологии в электронике. Выпуск 2: Сб. науч. тр. М.: Техносфера, 2013, с. 136-177.

17. Громов Д. Г., Гаврилов С. А., Редичев Е. Н., Аммосов Р. М. Кинетика процессов плавления-диспергирования тонких пленок меди // ФТТ, 2007, т. 49(1), с. 173-177.

Received 21.10.2019

Accepted 15.11.2019

\section{Thin Metal Films with Dispersion-Hardening Magnetic Layers of Fe-Cr-Co Alloy}

() 2019 V. S. Zayonchkovskiy ${ }^{\otimes 1}$, Aung Kyaw Kyaw ${ }^{1}$, I. M. Milyaev², N. S. Perov³ , I. A. Prokhorov ${ }^{4}$, A. A. Klimov ${ }^{5}$ A. V. Andreev6"

${ }^{1}$ Kaluga branch of Bauman Moscow State Technical University

2, Baghenova str., 248000 Kaluga, Russian Federation

${ }^{2}$ Baikov Institute of Metallurgy and Material Science of the Russian Academy of Sciences

49, Leninsky pr., 119334 Moscow, Russian Federation

${ }^{3}$ Faculty of Physics, Lomonosov Moscow State University

1, Leninskiye Gory, GSP-1, 119991 Moscow, Russian Federation

${ }^{4}$ Shubnikov Institute of Crystallography, Federal Scientific Research Centre "Crystallography and Photonics of the Russian Academy of Sciences

49, Leninsky pr., 119333 Moscow, Russian Federation

${ }^{5}$ Kotelnikov Institute of Radio Engineering and Electronics of the Russian Academy of Sciences

11-7, Mokhovaya str., 125009 Moscow, Russian Federation

${ }^{6}$ National Research University "Moscow Power Engineering Institute

14, Krasnokazarmennaya str., 111250 Moscow, Russian Federation

Vyacheslav S. Zayonchkovskiy, e-mail: zajonc4340@gmail.com 


\begin{abstract}
Purpose. The study of the magnetic properties and surface state of permanent magnet films, not containing precious metals, on a silicon substrate with a magnetization vector in the plane of the film.

Methods and methodology. Permanent magnet films are created by magnetron sputtering and subsequent single-stage high-vacuum rapid annealing. The structure of these magnets contains three layers: an adhesive layer of vanadium, a compensation layer of copper, and a ferromagnetic layer of a dispersion-hardening alloy (LDHA) of the Fe-Cr-Co system. The properties of the films were studied using confocal microscopy, X-ray diffractometry. A magnetic hysteresis loop was built using a vibromagnitometer and an assembly for the study of the magneto-optic Kerr effect. The morphology of the surface was studied using an atomic force microscope and a scanning electron microscope.

Results. After annealing, a significant bending of the substrates occurred, and with an insufficient thickness of the compensation layer, the destruction of both the film and part of the silicon substrate was observed. It was found that the increase in the coercive force of the films correlated with a high level of mechanical stresses in LDHA, characteristic for the decomposition of a supersaturated solid solution of chromium in iron in bulk materials.

For the preservation of the permanent magnet film, the thickness of the copper compensation layer must be not less than that of LDHA.

Conclusions. For the first time, a permanent magnet film was obtained, based on a layer of dispersion-hardening composition, not containing precious metals, with a level of coercive force sufficient for use in magnetoresistive integrated magnetic field sensors.
\end{abstract}

Keywords: magnetron sputtering, thin films, coercive force, vacuum annealing.

\section{ACKNOWLEDGEMENT}

For these studies, the NanoFocus confocal microscope was kindly provided by the management of the company Raster-Technology, Obninsk. Magnetic measurements were carried out using equipment purchased at the expense of the Moscow University State Development Program.

\section{CONFLICT OF INTEREST}

The authors declare the absence of obvious and potential conflicts of INTEREST related to the publication of this article.

\section{REFERENCES}

1. Masahiro Kitada, Yoshihisa Kamo, Hideo Tanabe. Magnetoresistive thin-film sensor with permanent magnet biasing film. Journal of Applied Physics, 1985, v. 58(4), pp. 1667-1670. DOI: https://doi.org/ $10.1063 / 1.336058$

2. Leo K. E. B. Serrona, Sugimura A., Fujisaki R., Okuda T., Adachi N., Ohsato H., Sakamoto I., Nakanishi A. Magnetic and structural properties of $\mathrm{NdFeB}$ thin film prepared by step annealing. Materials Science and Engineering B, 2003, v. 97(1), pp. 59-63. DOI: https://doi.org/10.1016/s0921-5107(02)00401-4

3. Hlopov B. V., Samoylova V. S., Yuryev I. A. Changes of a condition of thin-film layers of the magnetic materials applied in systems of external memory of magnetic hard dick. T-Comm., 2015, v. 9(12), pp. 5-11. (in Russ.)

4. Konoplev Yu. V., Izgorodin A. K. Structure formation, properties and application of hot-deformed alloys
UNDK and UNDCT. Available at: https://cyberleninka. $\mathrm{ru} /$ article/n/strukturoobrazovanie-svoystva-i-primenenie-goryachedeformirovannyh-splavov-yundk-iyundkt (accessed 24.10.2019)

5. Kaneko H., Homma M., Nakamura K. New ductile permanent magnet of $\mathrm{Fe}-\mathrm{Cr}-\mathrm{Co}$ system // AJP Conference Proceedings. 1972, no. 5, pp. 1088-1092. DOI: https://doi.org/10.1063/1.2953814

6. GOST 24897-81. Magnetic-hard deformable materials. Solid magnetik deformed materials. Marks. M.: Publishing House of Standards, 1981, 21 p. (in Russ.)

7. Ovsyannikov G. A., Petrzhik A. M., Borisenko I. V., Klimov A. A., Ignatov Yu. A., Demidov V. V., Nikita S. A. Magnetic transport characteristics of strained $\mathrm{La}_{0.7} \mathrm{Sr}_{0.3} \mathrm{MnO}_{3}$ epitaxial manganite films. J. Exp. Theor. Phys., 2009, v. 108(48), pp. 48-55. DOI: https://doi.org/10.1134/S1063776109010075

8. The website of the company "GEO-BAT". Available at: https://www.geo-ndt.ru/pribor-6855-rentgenoflyorescentnii-analizator-metekspert.htm (accessed 24.10.2019)

9. Kekalo I. B., Samarin B. A. Physical metallurgy of precision alloys. Alloys with special magnetic properties. Moscow, Metallurgy Publ., 1989, 496 p. (in Russ.)

10. Handbook of non-ferrous metals. Available at: https://ibmetal.ru/index.htm (accessed 24.10.2019)

11. Handbook of non-ferrous metals. Available at: http://metal-archive.ru/vanadiy/955-mehanicheskiesvoystva-vanadiya.html (accessed 24.10.2019)

12. Gromov D. G. Metallization of ultra-large integrated circuits. Tutorial / Eds: D. G. Gromov, A. I. Mochalov, A. D. Sulimin, V. I. Shevyakov. M: BINOM, 2012, 277 p. (in Russ.) 
13. Prokhorov I. A., Zakharov B. G. X-ray Diffraction Studies of Features of Relaxation and Distribution of Macro-Stresses in Epitaxial Structures. J. Surf. Invest.: X-Ray, Synchrotron Neutron Tech., 1999. no. 2, pp. 106-109. (in Russ.)

14. Stouney G. S. The Tension of Metallic Films Deposited by Electrolysis // Proceedings of the Royal Society A: Mathematical, Physical and Engineering Sciences, 1909, v. 82(553), pp. 172-175. DOI: https://doi. org/10.1098/rspa.1909.0021

15. Dobrynin V.A. On the applicability of the stony formula for calculation of mechanical stresses in thick films and coatings. Technical Physics Letters, 1997, v. 23(18), pp. 32-3613. (in Russ.)

16. Gromov D. G. The dimensional effect of melting in film structures of nanoelectronics. Nanotechnologies in electronics. Issue 2: Sat. Tr. M.: Technosphere Publ., 2013, pp. 136-177. (in Russ.)

17. Gromov D. G., Gavrilov S. A., Redichev E. N., Ammov R. M. Kinetics of the melting-dispersion process in copper thin films. Phys. of the Solid State, 2007, v. 49(1), pp. 178-184. DOI: https://doi.org/10.1134/ S1063783407010283
Зайончковский Вячеслав Станиславович к. ф.-М. н., доцент кафедры «Материаловедение и химия» Калужского филиала МГТУ им. Н. Э. Баумана, Калуга, Российская Федерация; е-mail: zajonc4340@gmail.com. ORCID iD: https://orcid 0000-0002-6519-6003.

Аунг Чжо Чжо - аспирант Калужского филиала МГТУ им. Н. Э. Баумана, Калуга, Российская Федерация; ORCID iD: https://orcid 0000-00018427-3046.

Миляев Игорь Матвеевич - д. ф.-М. н., в. н. с., Институт металлургии и материаловедения им. А. А. Байкова РАН, Москва, Российская Федерация.

Перов Николай Сергеевич - д. ф.-м. н., профессор, заведующий кафедрой магнетизма МГУ им. М. В. Ломоносова, Москва, Российская Федерация; ORCID iD: https://orcid: 0000-0002-07574942.

Прохоров Игорь Алексеевич - к. ф.-м. н., с. н. с., Институт кристаллографии им. А. В. Шубникова ФНИЦ «Кристаллография и фотоника» РАН, Москва, Российская Федерация.

Климов Алексей Анатольевич - к. ф.-м. н, с. н. с., Институт радиотехники и электроники им. В. А. Котельникова РАН, Москва, Российская Федерация.

Андреев Алексей Владимирович - магистр, Национальный исследовательский университет «МЭИ», Москва, Российская Федерация; инженер, Институт радиотехники и электроники им. В. А. Котельникова РАН, Москва, Российская Федерация; ORCID iD: https://orcid 0000-00027537-1629.
Vyacheslav S. Zayonchkovskiy - Cand. Sci. (Phys.Math.), Associate Professor of the Department of "Materials Science and Chemistry" of the Kaluga branch of Bauman Moscow State Technical University, Kaluga, Russian Federation; e-mail: zaj onc4340@gmail.com. ORCID iD: https://orcid 0000-0002-6519-6003.

Aung Kyaw Kyaw - graduate student of the Kaluga branch of Bauman Moscow State Technical University, Kaluga, Russian Federation; ORCID iD: https://orcid 0000-0001-8427-3046.

Igor M. Milyaev - Dr. Sci.(Phys.-Math.), Leading Researcher, Baikov Institute of Metallurgy and Material Science of the Russian Academy of Sciences, Moscow, Russian Federation.

Nikolay S. Perov - Dr. Sci. (Phys.-Math.), Professor, Head of the Department of Magnetism, Lomonosov Moscow State University, Russian Federation; ORCID iD: https://orcid: 0000-0002-07574942.

Igor A. Prokhorov - Cand. Sci. (Phys.-Math.), Senior Researcher, Shubnikov Institute of Crystallography, Federal Scientific Research Centre "Crystallography and Photonics of the Russian Academy of Sciences, Moscow, Russian Federation.

Alexey A. Klimov - Cand. Sci. (Phys.-Math.), Senior Researcher, Kotelnikov Institute of Radio Engineering and Electronics of the Russian Academy of Sciences, Moscow, Russian Federation.

Alexey V. Andreev - master, National Research University "Moscow Power Engineering Institute", Moscow, Russian Federation; Engineer, Kotelnikov Institute of Radio Engineering and Electronics of the Russian Academy of Sciences, Moscow, Russian Federation; ORCID iD: https://orcid 0000-00027537-1629. 